\title{
Associations between Resident Perceptions of the Local Residential Environment and Metabolic Syndrome
}

\author{
Katherine Baldock, ${ }^{1}$ Catherine Paquet,,${ }^{1,2}$ Natasha Howard, ${ }^{1}$ Neil Coffee, ${ }^{1}$ Graeme Hugo, ${ }^{3}$ \\ Anne Taylor, ${ }^{4}$ Robert Adams, ${ }^{5}$ and Mark Daniel ${ }^{1,6}$ \\ ${ }^{1}$ Social Epidemiology and Evaluation Research Group, Sansom Institute for Health Research and School of Health Sciences, \\ University of South Australia, Adelaide, SA 5001, Australia \\ ${ }^{2}$ Research Centre, Douglas Mental Health University Institute, Montreal, QC, Canada H4H $1 R 2$ \\ ${ }^{3}$ Discipline of Geography, Environment and Population, The University of Adelaide, Adelaide, SA 5000, Australia \\ ${ }^{4}$ Population Research and Outcome Studies, Discipline of Medicine, The University of Adelaide, Adelaide, SA 5000, Australia \\ ${ }^{5}$ The Health Observatory, The Queen Elizabeth Hospital Campus, The University of Adelaide, Adelaide, SA 5011, Australia \\ ${ }^{6}$ Department of Medicine, St Vincent's Hospital, The University of Melbourne, Fitzroy, VIC 3065, Australia
}

Correspondence should be addressed to Katherine Baldock, katherine.baldock@mymail.unisa.edu.au

Received 30 April 2012; Accepted 14 August 2012

Academic Editor: Mahfuzar Rahman

Copyright ( $\odot 2012$ Katherine Baldock et al. This is an open access article distributed under the Creative Commons Attribution License, which permits unrestricted use, distribution, and reproduction in any medium, provided the original work is properly cited.

A substantial body of research has arisen concerning the relationships between objective residential area features, particularly area-level socioeconomic status and cardiometabolic outcomes. Little research has explored residents' perceptions of such features and how these might relate to cardiometabolic outcomes. Perceptions of environments are influenced by individual and societal factors, and may not correspond to objective reality. Understanding relations between environmental perceptions and health is important for the development of environment interventions. This study evaluated associations between perceptions of local built and social environmental attributes and metabolic syndrome, and tested whether walking behaviour mediated these associations. Individual-level data were drawn from a population-based biomedical cohort study of adults in Adelaide, South Australia (North West Adelaide Health Study). Participants' local-area perceptions were analysed in cross-sectional associations with metabolic syndrome using multilevel regression models $(n=1,324)$. A nonparametric bootstrapping procedure evaluated whether walking mediated these associations. Metabolic syndrome was negatively associated with greater local land-use mix, positive aesthetics, and greater infrastructure for walking, and was positively associated with greater perceived crime and barriers to walking. Walking partially mediated associations between metabolic syndrome and perceived environmental features. Initiatives targeting residents' perceptions of local areas may enhance the utility of environmental interventions to improve population health.

\section{Introduction}

The rising prevalence of cardiometabolic diseases, including type 2 diabetes and cardiovascular disease, presents a major international public health challenge for the 21st century [1]. Public health prevention efforts to combat these diseases have largely focused on identifying and reducing individuallevel risk factors, particularly physical inactivity and poor nutrition. Such prevention strategies alone, however, have had poor utility against increasing morbidity and mortality attributable to cardiometabolic diseases at the population level $[2,3]$. There is a growing recognition that strategies which target individual behaviours in addition to the context within which such behaviours arise can have the greatest public health impact [4]. This has led to a rapidly increasing body of research on the role of residential, or local-area, environments in patterning cardiometabolic risk factors and subsequent disease.

Consistent associations have been established between measures of area socioeconomic status and cardiometabolic diseases [5-7]. Fewer studies have examined other area features, such as road traffic [8], population density [9], or neighbourhood social cohesion [10]. A growing body of evidence demonstrates relations between resident perceptions 
of local area features and risk factors for cardiometabolic diseases, particularly physical activity and obesity. Body mass index and physical activity are associated with perceived environmental features often indicative of more "walkable" areas, such as greater land-use mix [11-13], infrastructure for walking $[12,14,15]$, positive aesthetics [11-13, 15-19], and safety from crime [19-25]. Limited research, however, has examined perceived environmental features in relation to a measured cardiometabolic outcome.

Recent research makes clear the public health importance of understanding and targeting resident perceptions of their local area $[26,27]$. However, although perceptions of environmental features are frequently used to represent the objective reality [28], several studies have shown a general lack of correspondence between perceived and objective measures of environments $[29,30]$. In order to better understand perceptions of environments as they relate to health outcomes, it is essential to improve the conceptualisation of perceptual measures.

Perceptions of environmental features reflect an individual's interaction with a particular environment, involving both perception, with inputs from the visual, haptic, auditory, and other senses [31], and proprioception, the experience of one's own body in space [32]. These multisensory inputs are integrated to form a cognitive representation of the environment. The understanding and meaning subsequently attached to these cognitive representations are influenced by factors such as language, social class, personal values, place attachment, culture, social norms, past experiences, physical capacity, and individual personality characteristics [29, $33,34]$. Perceptions of environments thus constitute a mix of individual and broader societal factors, and are not simply proxy measures for specific objective environmental features.

Blacksher and Lovasi [27] have argued that inadequate attention has been given to people's understandings of their neighbourhood in developing built environment interventions. They suggest that the primary supposition in much place and health research is that changes to the built environment will lead to positive changes in behaviour for those within the changed environment, thereby resulting in better health. Yet, a limited understanding of the relationship between environmental perceptions and health outcomes, and the pathways linking perceptions to health, may yield ineffective built environment interventions aimed at improving health. For example, the availability or accessibility of environmental features presumed to be important for health may have little effect on health outcomes if they are not perceived to be available or accessible [35].

In addition to the need for evaluating relations between perceived environmental attributes and cardiometabolic outcomes, it is important to explore the mechanisms that may underpin such relations. It has been proposed that environmental perceptions may predict cardiometabolic health indirectly through behaviours such as physical activity [36], adverse emotional and affective states, and chronic stress [37, 38 ], and directly through harmful psychological and physiological responses that contribute to the development of obesity and cardiometabolic diseases [37, 39, 40]. Few studies, however, have formally tested the pathways of such associations; for example, whether physical activity mediates the associations between perceived environmental features and health outcomes [41]. Information regarding explanatory mechanisms is essential, however, to improving our understanding of causal processes.

This study aimed to evaluate whether perceived features of local residential areas were associated with a clinically measured cardiometabolic outcome, namely, metabolic syndrome. Metabolic syndrome is a clustering of clinical risk factors strongly predictive of cardiometabolic diseases [42-44]. It has utility as a metric for evaluating area-level relationships between environmental factors and population-level risk for cardiometabolic outcomes $[37,45]$. A secondary aim was to assess whether associations between perceived environmental features and metabolic syndrome were mediated by walking behaviour.

\section{Methods}

2.1. Study Sample. This cross-sectional investigation used data from the North West Adelaide Health Study (NWAHS) conducted in Adelaide, Australia. The NWAHS is a longitudinal representative cohort of 4,056 randomly selected adults aged 18 years and over, originally recruited between 2000 and 2003 from the northern and western metropolitan regions of Adelaide [46, 47]. In 2001, the north west region comprised $38 \%$ of the Adelaide metropolitan population, and 28\% of the South Australian population [48]. Three waves of data collection for the NWAHS have been undertaken to date. NWAHS data collected across Wave 2 (2004-2007) were utilised for this cross-sectional analysis, this being the only period for which all required measures were available. Information on self-reported sociodemographic variables and health behaviours were collected via telephone interview. Participants attended a clinic where biomedical measurements were taken. Information on current medications prescribed for participants was obtained by linking Australian Pharmaceutical Benefits Scheme (PBS) data to each individual participant using their Medicare number. Perceptions of local residential area features were obtained via postal or online questionnaire. All participants with a valid residential address were assigned a georeference corresponding to their place of residence at the time of the Wave 2 clinic visit. Socioeconomic measures pertaining to residential areas were represented at the State Suburb level. Suburbs are formed by aggregating Census Collection Districts [49]. Relative to alternate area-level units, the Suburb provides strong between-unit variability while avoiding the problem of small cluster sizes associated with using smaller spatial units such as Census Collection Districts. This study was approved by the Ethics of Human Research Committees of the Central Northern Adelaide Health Service, the University of South Australia, and the South Australian Department of Health.

\subsection{Measures}

2.2.1. Outcome Measure. Metabolic syndrome was classified using the International Diabetes Federation criteria [50], including central obesity (defined as waist circumference 
$\geq 94 \mathrm{~cm}$ for Europid men and $\geq 90 \mathrm{~cm}$ for non-Europid men, and $\geq 80 \mathrm{~cm}$ for Europid and non-Europid women), plus any two of the following four factors: raised triglyceride level $(>1.7 \mathrm{mmol} / \mathrm{L})$; reduced HDL cholesterol $(<1.03 \mathrm{mmol} / \mathrm{L}$ in males and $<1.29 \mathrm{mmol} / \mathrm{L}$ in females), or treatment for lipid abnormality; raised blood pressure (systolic blood pressure $\geq 130$ or diastolic blood pressure $\geq 85 \mathrm{~mm} \mathrm{Hg}$ ), or treatment for hypertension; raised fasting plasma glucose (FPG; $\geq 5.6 \mathrm{mmol} / \mathrm{L}$ ), or previously diagnosed type 2 diabetes. Biomedical examinations for obtaining waist circumference, triglyceride, HDL cholesterol, blood pressure and FPG measurements were undertaken at one of two hospital-based clinics. A structured protocol was followed by trained clinic staff conducting the biomedical examinations. A fasting blood sample of approximately $30 \mathrm{~mL}$ was taken as part of the biomedical examination for obtaining triglyceride, HDL cholesterol, and FPG levels. Blood pressure was measured using a standard, calibrated sphygmomanometer. The average of two readings, taken five to ten minutes apart while the participant was seated and relaxed, was used. Waist circumference was measured to the nearest 0.1 centimetre using an inelastic tape maintained in a horizontal plane, with the subject standing comfortably with weight distributed evenly on both feet. The measurement was taken at the level of the narrowest part of the waist. Physician-diagnosed type 2 diabetes was reported by respondents via telephone interview and written questionnaire. International Diabetes Federation metabolic syndrome criteria for dyslipidaemia or hypertension were considered met if a participant had been prescribed medication to treat such conditions in the six months prior to their Wave 2 clinic attendance.

2.2.2. Perceptions of the Local Residential Environment. Perceptions of local-area features were assessed using six subscales of the Australian version of the Neighbourhood Environment Walkability Scale (NEWS-AU) [51], a modified version of the NEWS [52]. This scale captures several dimensions of the local built and social environmental context which could influence cardiometabolic outcomes through walking behaviour. The items from the following six subscales were used in this analysis: land-use mix - diversity, access to services, infrastructure for walking/cycling, aesthetics, traffic safety, and crime safety. All items were rated on a four-point Likert scale, except land-use mix - diversity. The land-use mix - diversity subscale assesses perceived walking proximity to 24 types of stores and resources (e.g., supermarket, library, or park), for which the scorable walking distance ranged across five categories from 1-5 minutes to more than 30 minutes. Resources included in the landuse mix - diversity subscale were defined for this analysis as being locally available if perceived to be within a 20-minute walking distance from home (approximately equivalent to 1.6 kilometres or 1 mile) $[53,54]$. The number of different types of locally available resources was summed to give a score out of 24, indicating local land-use mix. This score was then standardised to give a mean of zero and a standard deviation of 1 .

Recently, Cerin and colleagues [55] recommended a modified scoring procedure for the NEWS-AU, based on the results of a factor analysis of all subscales except landuse mix - diversity. This subscale was excluded from the factor analysis due to the nature of the scale and response format. In our sample, application of this NEWS-AU scoring procedure resulted in a modest internal consistency (Cronbach's alpha) for certain subscales: infrastructure for walking/cycling $=0.64$, traffic load $=0.68$, and traffic safety $=0.45$. The other subscales demonstrated acceptable internal consistency: access to services $=0.81$, aesthetics $=0.77$, and crime $=0.79$. To improve the internal consistency of the perceived environment measures and find the most appropriate item structure for our sample, an exploratory factor analysis was undertaken with the items rated on a four-point scale from the NEWS-AU [51] subscales access to services, infrastructure for walking/cycling, aesthetics, traffic safety, and crime safety. Following the rationale of Cerin and colleagues [56], the land-use mix - diversity subscale was excluded from the factor analysis. The standardised factor scores from this exploratory factor analysis were retained and used in subsequent analyses to represent perceived environmental features, along with the standardised local land-use mix score. Higher values for the local land-use mix, aesthetics, infrastructure for walking, and access to services measures indicate more positive perceptions of those area features. Higher scores on the crime and barriers to walking factors indicate more negative perceptions of those area features.

2.2.3. Mediator. Walking behaviour was measured via a single item in a self-report questionnaire, which asked respondents to report the total amount of time (in hours and minutes) they had spent walking for sport, recreation or fitness in the previous two weeks. The survey item was replicated from the Australian National Health Surveys undertaken in 2001 and 2004 [57], and has demonstrated acceptable testretest reliability [58]. Walking behaviour in this study was expressed as the average time spent walking over one week.

2.2.4. Covariates. Self-reported socio-demographic characteristics included: age, sex, marital status assessed as married/living with partner or not partnered, annual household income assessed as $\$ 20,000$ or less, $\$ 20,001$ to $\$ 60,000$, or greater than $\$ 60,000$, work status assessed as employed or not employed, and educational attainment assessed as less than Bachelor's degree, or Bachelor's degree or higher. There were $n=10(0.8 \%)$ missing data for educational attainment and $n=34(2.6 \%)$ missing data for household income at Wave 2 of the NWAHS. Missing values for these variables were replaced by Wave 1 values, to avoid loss of Wave 2 observations. Median weekly household income was utilised as a measure of area-level socioeconomic status. This measure, extracted at the suburb level from the 2006 Australian Bureau of Statistics Census of Population and Housing [59], was ascribed to each participant.

\subsection{Data Analysis}

2.3.1. Exploratory Factor Analysis of NEWS-AU Items. An exploratory factor analysis was undertaken in SPSS (version 18.0, SPSS Inc., Chicago, IL, USA) for participants with 


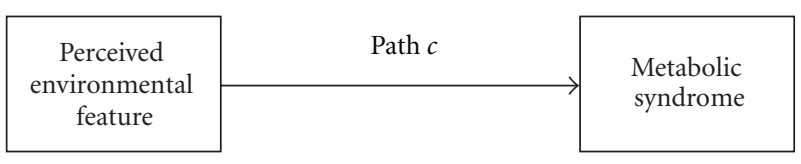

(a)

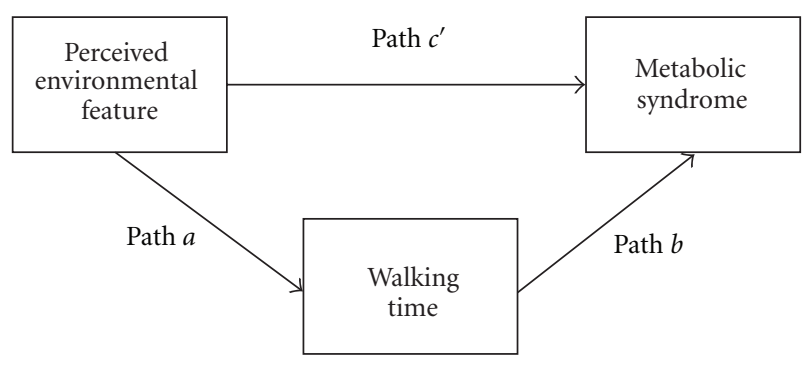

(b)

FIGURE 1: (a) Direct association between perceived environmental features and metabolic syndrome. (b) Indirect association between perceived environmental features and metabolic syndrome through walking time.

complete data on all items to be factor analysed. The principal components method with an oblique rotation was used to allow for a correlated factor structure. Eigenvalues and scree plots were examined for all solutions. Factor structures were compared with the original NEWS, the NEWS$\mathrm{AU}$, and the respecified NEWS-AU structures. Several factor extractions were attempted in order to achieve a parsimonious model conceptually comparable to the original scales.

\subsubsection{Evaluation of Associations between Perceived Environ-} mental Features, Walking Time, and Metabolic Syndrome. Associations between perceived environmental features, walking time, and metabolic syndrome were assessed for participants with data for all measures using a series of multilevel regression models that accounted for the clustering of individuals within suburbs. Individuals were modelled at the first level, and suburbs at the second level, using the SAS (version 9.1.3; SAS Institute Inc., Cary, NC, USA) glimmix procedure. The mediating role of walking time in associations between environmental perceptions and metabolic syndrome was evaluated using the criteria of Baron and Kenny [60]. Figures 1(a) and 1(b) present the paths to be tested under these criteria. All analyses included participant age, sex, marital status, income, education, work status, and area-level income; subsequent models also included walking time. Direct associations between each perceived environmental feature and metabolic syndrome (Path $c$ ), and indirect associations between each perceived environmental feature and metabolic syndrome, accounting for walking time (Path $c^{\prime}$ ), were estimated in separate models using multilevel logistic regression. To formally test the mediating effect of walking time, associations between each perceived environmental feature and walking time (Path a) were estimated using multilevel Poisson regression, and associations between walking time and metabolic syndrome, controlling for each perceived environmental feature (Path $b$ ), were estimated in separate multilevel logistic regression models. Mediated (indirect) effects were then formally tested using a nonparametric bootstrapping procedure $(n=20,000$ samples) [61] which estimates the sampling distribution of the indirect effect $(a b)$ and the corresponding 95\% confidence interval (CI). We used this method because it is one of the more valid and powerful methods for testing intervening, or mediating, variable effects, particularly where the indirect effect is not normally distributed, and for multilevel models with binary outcomes [62]. Indirect effects were considered significant when the 95\% CI did not include zero. For all tests, statistical significance was considered at $P=0.05$.

\section{Results}

A total of $n=1,656$ individuals provided complete responses to questions on perceptions of access to services, infrastructure for walking/cycling, aesthetics, traffic safety, and crime safety in the local area. Data from these participants were used in the factor analysis of NEWS-AU items. Of these 1,656 participants, those with missing information for the local landuse mix subscale, clinical measurements, demographic information, and self-reported walking time $(n=320)$, and those without a valid residential address who could not be ascribed an area-level income value $(n=12)$ were excluded from subsequent analyses. Table 1 presents the demographic characteristics of the final analytic sample $(n=$ 1,324). Participants in this sample were clustered within 201 Suburbs, with a median of three participants per Suburb (interquartile range $=8$ ). The prevalence of metabolic syndrome in this sample was $35.2 \%$ (95\% CI 32.7, 37.8).

3.1. Exploratory Factor Analysis of NEWS-AU Items. Initial factor analysis solutions for the 31 NEWS-AU items analysed yielded either too many or too few factors for meaningful interpretation, based on the eigenvalues $>1$ criterion and scree plot. In order to compare more directly with the NEWS and two NEWS-AU structures, we forced a six- and a fivefactor solution. The six-factor solution was very similar to the re-specified NEWS-AU structure determined for this scale by Cerin et al. [55], but the derived factors in our sample did not all demonstrate acceptable reliability as determined by Cronbach's alpha. A five-factor solution was selected for further analysis due to its parsimony, reliability, and similarity to the original NEWS subscales. The five correlated factors accounted for $45.6 \%$ of the total variance (Table 2), and represented aesthetics, crime, infrastructure for walking, access to services and barriers to walking in the local area. The factor infrastructure for walking was reverse scored to be interpreted in the same direction as the original items included in the factor. The factor structure, including item loadings, is presented in Table 3. 
TABLe 1: Demographic characteristics of the sample $(n=1,324)$.

\begin{tabular}{|c|c|c|}
\hline & $n$ & Mean $(\mathrm{SD})$ or $\%(95 \% \mathrm{CI})$ \\
\hline Age (years) & 1324 & $54.3(14.3)$ \\
\hline \multicolumn{3}{|l|}{ Sex } \\
\hline Male (\%) & 609 & $46.0(43.3-48.7)$ \\
\hline Female (\%) & 715 & $54.0(51.3-56.7)$ \\
\hline \multicolumn{3}{|l|}{ Marital status } \\
\hline Married, living with partner (\%) & 916 & $69.2(66.7-71.6)$ \\
\hline Separated, divorced, widowed, never married (\%) & 408 & $30.8(28.3-33.3)$ \\
\hline \multicolumn{3}{|l|}{ Education level } \\
\hline Less than Bachelor degree (\%) & 1139 & $86.0(84.1-87.8)$ \\
\hline Bachelor degree or higher (\%) & 185 & $14.0(12.2-15.9)$ \\
\hline \multicolumn{3}{|l|}{ Annual household income } \\
\hline Less than $\$ 20,001(\%)$ & 298 & $22.5(20.3-24.8)$ \\
\hline$\$ 20,001$ to $\$ 60,000(\%)$ & 633 & $47.8(45.1-50.5)$ \\
\hline More than $\$ 60,000(\%)$ & 393 & $29.7(27.3-32.2)$ \\
\hline \multicolumn{3}{|l|}{ Work status } \\
\hline Employed (\%) & 735 & $55.5(52.8-58.2)$ \\
\hline Not employed (\%) & 589 & $44.5(41.8-47.2)$ \\
\hline Area-level median weekly household income (AUD) & 1324 & $864.05(201.36)$ \\
\hline Walking time in previous week (mins) & 1324 & $113.4(196.8)$ \\
\hline
\end{tabular}

TABle 2: Characteristics of factors derived from the Australian version of the Neighbourhood Environment Walkability Scale $(n=$ $1,656)$.

\begin{tabular}{lccc}
\hline Factor & $\begin{array}{c}\text { No. of } \\
\text { items }\end{array}$ & $\begin{array}{c}\text { Percent of variance } \\
\text { explained }\end{array}$ & $\begin{array}{c}\text { Cronbach's } \\
\text { alpha }^{\text {a }}\end{array}$ \\
\hline Aesthetics & 6 & 17.75 & 0.73 \\
Crime & 6 & 11.78 & 0.80 \\
Infrastructure for walking & 10 & 6.05 & 0.74 \\
Access to services & 3 & 5.20 & 0.85 \\
Barriers to walking & 6 & 4.79 & 0.58 \\
\hline
\end{tabular}

${ }^{\text {a }}$ Based on items with loadings $\geq 0.4$.

3.2. Associations between Environmental Perceptions and Metabolic Syndrome, and the Mediating Effect of Walking Behaviour (Paths $c$ and $c^{\prime}$ ). All but one of the perceived environmental features were associated with the presence of metabolic syndrome, in models accounting for participant age, sex, marital status, income, education, work status, and area-level income (Path $c$, Table 4). Attributes of the perceived environment that were negatively associated with metabolic syndrome included local land-use mix, aesthetics, and infrastructure for walking in the local area. Perceived environmental features positively associated with metabolic syndrome included crime and barriers to walking in the local area. Access to services was not associated with having metabolic syndrome. With the inclusion of walking time, the effect of perceived environmental features on metabolic syndrome generally remained unchanged (Path $c^{\prime}$, Table 4) indicating limited mediation by walking behaviour.
3.3. Associations between Environmental Perceptions and Walking Time (Path a). All but one of the perceived environmental attributes were associated with walking time in the expected direction, accounting for covariates. Perceived environmental features positively related to walking included: local land-use mix (estimate $=0.08$ (95\% CI 0.08, 0.09), $P<0.0001)$, aesthetics (estimate $=0.06$ (95\% CI 0.06, 0.07), $P<0.0001)$, and access to services (estimate $=0.17(95 \% \mathrm{CI}$ $0.16,0.18), P<0.0001)$. Perceived environmental features negatively related to walking included: crime (estimate $=$ -0.10 (95\% CI $-0.11,-0.10), P<0.0001)$ and barriers to walking (estimate $=-0.03(95 \% \mathrm{CI}-0.04,-0.03), P<$ $0.0001)$. The infrastructure for walking factor was associated with walking, but not in the expected direction (estimate = -0.02 (95\% CI $-0.03,-0.01), P<0.0001)$.

3.4. Associations between Walking Time and Metabolic Syndrome, Adjusting for Environmental Perceptions (Path $b$ ). The number of minutes walked over one week was associated with metabolic syndrome, while adjusting for covariates and each perceived environmental feature. In all models accounting for covariates and each individual perceived environmental feature, walking time was negatively associated with having metabolic syndrome (OR $=0.97$ (95\% CI 0.95, 0.99), $P<=0.005)$.

3.5. Indirect Effect of Walking Time in Associations between Environmental Perceptions and Metabolic Syndrome. The indirect effect of walking was formally tested where both path $a$ (association between each perceived environment feature and walking time) and path $b$ (association between walking time and metabolic syndrome) were significant. Estimates 
TABle 3: Factor structure of the Australian version of the Neighbourhood Environment Walkability Scale $(n=1,656)$.

\begin{tabular}{|c|c|c|c|c|c|c|}
\hline \multirow{2}{*}{ Item no. ${ }^{a}$} & \multirow{2}{*}{ Item } & \multicolumn{5}{|c|}{ Item loading on each factor ${ }^{b}$} \\
\hline & & Factor 1 & Factor 2 & Factor 3 & Factor 4 & Factor 5 \\
\hline$\overline{\mathrm{A} 1}$ & Can do most shopping & & & & 0.81 & \\
\hline A2 & Many shops within easy walking distance & & & & 0.89 & \\
\hline A3 & Many places to go within easy walking distance & & & & 0.85 & \\
\hline A4 & Easy to walk to public transport stop & & & -0.54 & & \\
\hline A5 & Streets in local area are hilly & & & 0.39 & & \\
\hline A6 & Major barriers to walking & & & & & 0.53 \\
\hline A7 & Car parking difficult in shopping areas & & & & & 0.50 \\
\hline $\mathrm{B} 1$ & Footpaths on most of the streets & & & -0.75 & & \\
\hline $\mathrm{B} 2$ & Footpaths are well maintained & & & -0.63 & & \\
\hline B3 & Park or nature reserve easily accessible & & & -0.43 & & \\
\hline B4 & Grass/dirt strip separating streets from footpaths & & & -0.58 & & \\
\hline B5 & Footpaths separated from road/traffic by parked cars & & & & & 0.28 \\
\hline B6 & Bicycle or walking paths easily accessible & & & -0.50 & & \\
\hline $\mathrm{C} 1$ & Lots of greenery around the local area & 0.63 & & & & \\
\hline $\mathrm{C} 2$ & Tree cover or canopy along footpaths & 0.50 & & & & \\
\hline $\mathrm{C} 3$ & Many interesting things to look at & 0.74 & & & & \\
\hline $\mathrm{C} 4$ & Local area free from litter, rubbish, or graffiti & & 0.53 & & & \\
\hline C5 & Attractive buildings and homes & 0.67 & & & & \\
\hline C6 & Pleasant natural features & 0.70 & & & & \\
\hline D1 & Lots of traffic along most nearby streets & & & & & 0.68 \\
\hline D2 & Live on or near main arterial road or throughway for motor vehicles & & & & & 0.58 \\
\hline D3 & Speed of traffic usually slow & 0.29 & & & & \\
\hline D4 & Many traffic slowing devices & & & -0.38 & & \\
\hline D5 & Busy streets have pedestrian crossings and traffic signals & & & -0.50 & & \\
\hline D6 & A lot of exhaust fumes & & & & & 0.61 \\
\hline E1 & Streets are well lit at night & & & -0.51 & & \\
\hline E2 & A lot of petty crime & & 0.78 & & & \\
\hline E3 & A lot of major crime & & 0.79 & & & \\
\hline E4 & Level of crime makes it unsafe to walk during the day & & 0.66 & & & \\
\hline E5 & Level of crime makes it unsafe to walk at night & & 0.82 & & & \\
\hline E6 & Feel safe walking home from a bus or train stop at night & & -0.62 & & & \\
\hline
\end{tabular}

${ }^{\mathrm{a}}$ NEWS-AU subscales: [51] A: access to services; B: infrastructure for walking/cycling; C: aesthetics; D: traffic safety; E: crime safety. ${ }^{\text {b} F a c t o r s ~ d e r i v e d ~ f r o m ~ t h i s ~}$ analysis: factor 1: aesthetics; factor 2: crime; factor 3: infrastructure for walking; factor 4: access to services; factor 5: barriers to walking.

TABLE 4: Multivariable associations between each feature of the perceived environment and metabolic syndrome $(n=1,324)$.

\begin{tabular}{|c|c|c|c|c|c|c|}
\hline & \multicolumn{3}{|c|}{ Model 1, Path c ${ }^{\mathrm{a}}$} & \multicolumn{3}{|c|}{ Model 2, Path $\mathrm{c}^{\prime b}$} \\
\hline & Odds ratio & $95 \% \mathrm{CI}$ & $P$ value & Odds ratio & $95 \% \mathrm{CI}$ & $P$ value \\
\hline Local land-use mix & 0.87 & $0.77,1.00$ & 0.04 & 0.87 & $0.77,1.00$ & 0.04 \\
\hline Aesthetics & 0.88 & $0.77,1.00$ & 0.04 & 0.88 & $0.78,1.00$ & 0.06 \\
\hline Crime & 1.15 & $1.01,1.31$ & 0.04 & 1.15 & $1.01,1.31$ & 0.04 \\
\hline Infrastructure for walking & 0.85 & $0.75,0.97$ & 0.01 & 0.85 & $0.75,0.97$ & 0.02 \\
\hline Access to services & 0.93 & $0.82,1.05$ & 0.24 & 0.95 & $0.84,1.07$ & 0.39 \\
\hline Barriers to walking & 1.16 & $1.03,1.32$ & 0.02 & 1.16 & $1.02,1.31$ & 0.02 \\
\hline
\end{tabular}

${ }^{a}$ Adjusted for participant age, sex, marital status, income, education, work status, and area-level income. ${ }^{b}$ Adjusted for participant age, sex, marital status, income, education, work status, area-level income, and walking time.

of the indirect effect of walking time are presented in Table 5. Walking time mediated associations between metabolic syndrome and local land-use mix, aesthetics, crime, access to services and barriers to walking. These indirect effects were small, however none of the 95\% CIs encompassed zero. The indirect effect of walking was strongest in associations between metabolic syndrome and perceived access to services and crime. 
TABLE 5: Indirect effect of walking time in associations between perceived environmental features and metabolic syndrome $(n=$ $1,324)$.

\begin{tabular}{lcc}
\hline $\begin{array}{l}\text { Perceived } \\
\text { environmental feature }\end{array}$ & $\begin{array}{c}\text { Indirect effect } \\
\text { estimate }(a b)\end{array}$ & $95 \%$ CI \\
\hline Local land-use mix & -0.00253 & $-0.00428,-0.000692$ \\
Aesthetics & -0.00196 & $-0.00337,-0.000595$ \\
Crime & 0.00314 & $0.000960,0.00538$ \\
Access to services & -0.00530 & $-0.00906,-0.00161$ \\
Barriers to walking & 0.00097 & $0.000307,0.00174$ \\
\hline
\end{tabular}

\section{Discussion}

This cross-sectional study of adults drawn from a metropolitan area demonstrated consistent relationships between residents' perceptions of local-area attributes and metabolic syndrome. Walking behaviour was a weak, partial mediator of these associations.

Previous research investigating relations between neighbourhoods and cardiometabolic diseases has largely represented local residential areas using measures of area-level socioeconomic status. These studies have demonstrated associations between area-level socioeconomic deprivation and ischaemic heart disease mortality [63], coronary heart disease mortality $[64,65]$, coronary heart disease incidence $[5$, $6,66]$, coronary heart disease risk factors [67], type 2 diabetes incidence [7], and components of the insulin resistance syndrome [68]. Other studies have found that individual socioeconomic factors largely accounted for associations between area deprivation and coronary heart disease [69-72].

Research investigating cardiometabolic diseases in relation to features of environments other than socioeconomic status has evidenced a variety of associations. For instance, ischaemic heart disease is associated with population density [9] and neighbourhood residential stability [73]. Coronary heart disease has been linked to neighbourhood crime [74, $75]$, exposure to road traffic $[8,76]$, and neighbourhood social capital [77]. Insulin resistance is associated with distance to wealthy areas [78], and acute myocardial infarction mortality is similarly associated with neighbourhood social cohesion and perceived safety [10]. The majority of these studies tended to examine only one measure of the residential environment other than area-level socioeconomic status in relation to cardiometabolic health outcomes. The present study extends this body of research in demonstrating associations between a number of specific perceived features of the built and social environment and a clinically measured cardiometabolic outcome.

Knowledge of perceived environmental features that are related to cardiometabolic outcomes is relevant to the development of environmental interventions aimed at improving health. Changes in the environment may also require educational interventions targeting residents' perceptions of the environment. For example, the introduction of large scale food retailing in a disadvantaged community in the United Kingdom had little effect in improving diet and health [79]. A study from the United States similarly found that local availability of supermarkets and grocery stores was not related to diet quality [80]. It may be that use of local fresh food stores is related to residents' perceptions of food availability and affordability which could be improved through more targeted interventions, for example campaigns aimed at food awareness, affordability, and acceptability [35].

In addition to identifying the perceived features of residential environments associated with metabolic syndrome, efforts to elucidate the mechanisms underlying these associations can aid in understanding causal processes. Such knowledge is important for supporting the development of public health interventions [81]. Studies exploring physical activity as a mediator that links perceptions of various localarea attributes to cardiometabolic risk have shown mixed results. Some studies have presented results suggestive of mediation by physical activity $[41,82,83]$. Other studies have not found evidence for mediation by physical activity [10, 84]. Research linking local-area socioeconomic indicators to cardiometabolic health through physical activity has also had mixed findings. Some studies have indicated partial mediation by physical activity $[85,86]$, while others have not $[13,14]$. Only two studies have assessed physical activity as a mediator independent of other risk factors for cardiometabolic disease $[41,84]$. None of the other studies reviewed here $[10,13,14,82,83,85,86]$ could therefore determine the specific effect of physical activity as a mediator. Just one study thus far published has formally tested the statistical significance of the mediated effect of physical activity [41].

In our sample, walking behaviour was a weak, though statistically significant mediator linking a range of perceived features of the local residential environment to metabolic syndrome. The stronger indirect effect of walking in associations between metabolic syndrome and perceived access to services and crime may have been influenced by the stronger associations between these two perceived environmental features and walking behaviour, compared to other environmental features. The indirect effect of walking was smaller for the other perceived environmental features, and generally weak for all perceived environmental features; however, other potential untested mediators such as chronic stress [37, 38] may be operating in these associations.

An unexpected finding in this study was that positive perception of infrastructure for walking was inversely related to walking time. It is possible that the perceived presence of infrastructure for walking alone may not be a sufficient support for greater walking. For example, greater walking may require positive infrastructure as well as perceived access to a range of destinations or services. Alternatively it is possible that a third, unmeasured variable related to both perceptions of infrastructure for walking and walking behaviour could explain this result (i.e., residual confounding). Due to the cross-sectional nature of this study, it is also possible that reverse causality is in effect: that reduced walking behaviour means that residents are not aware of the problematic or unsupportive infrastructure for walking.

Comprehensive measurement of the perceived local residential environment, clinically measured metabolicsyndrome, and formal mediation analysis in a large population-based sample are the main strengths of this study. 
Limitations of this study include the fact that analyses were based on cross-sectional data. Hence, while the direction of associations can be hypothesised, these remain to be properly assessed using longitudinal data. Other potential mediating factors, not tested in the present study due to lack of suitable measures, could also influence environment-health relationships, including diet and chronic stress.

Our data indicate that perceived measures of the local residential environment are related to metabolic syndrome. Walking behaviour was a weak statistical mediator of this association. Whether this weak association reflects the characteristics of our measure, or other untested mediators including psychosocial factors and chronic stress, remains to be determined. These findings suggest that public health and urban planning strategies aimed at improving population health by changing environments might also consider targeting residents' perceptions of area features, as a means to enhance the effectiveness of such interventions.

\section{Acknowledgments}

The Social Epidemiology and Evaluation Research Group at the University of South Australia in collaboration with the South Australian Department of Health conducted this research under National Health and Medical Research Council (NHMRC) Projects (no. 631917 and no. 570150) investigating the relationships between place and metabolic syndrome (PAMS). This paper has been reviewed for scientific content and consistency of data interpretation by Chief Investigators of the North West Adelaide Health Study (NWAHS). The authors are grateful for the interest and commitment of cohort participants. They appreciate the contributions of research support staff involved in recruitment and clinical followup.

\section{References}

[1] P. Zimmet, K. G. M. M. Alberti, and J. Shaw, "Global and societal implications of the diabetes epidemic," Nature, vol. 414, no. 6865, pp. 782-787, 2001.

[2] P. Nilsson and G. Berglund, "Prevention of cardiovascular disease and diabetes: lessons from the Malmö Preventive Project," Journal of Internal Medicine, vol. 248, no. 6, pp. 455462, 2000

[3] Y. D. Miller and D. W. Dunstan, "The effectiveness of physical activity interventions for the treatment of overweight and obesity and type 2 diabetes," Journal of Science and Medicine in Sport, vol. 7, no. 1, supplement, pp. 52-59, 2004.

[4] L. Berkman and I. Kawachi, "A historical framework for social epidemiology," in Social Epidemiology, L. Berkman and I. Kawachi, Eds., pp. 3-12, Oxford University Press, New York, NY, USA, 2000

[5] K. Sundquist, M. Malmström, and S. E. Johansson, "Neighbourhood deprivation and incidence of coronary heart disease: a multilevel study of 2.6 million women and men in Sweden," Journal of Epidemiology and Community Health, vol. 58, no. 1, pp. 71-77, 2004.

[6] A. V. Diez Roux, S. S. Merkin, D. Arnett et al., "Neighborhood of residence and incidence of coronary heart disease," The New England Journal of Medicine, vol. 345, no. 2, pp. 99-106, 2001.
[7] S. Krishnan, Y. C. Cozier, L. Rosenberg, and J. R. Palmer, "Socioeconomic status and incidence of type 2 diabetes: results from the Black Women's Health Study," American Journal of Epidemiology, vol. 171, no. 5, pp. 564-570, 2010.

[8] W. Q. Gan, L. Tamburic, H. W. Davies, P. A. Demers, M. Koehoorn, and M. Brauer, "Changes in residential proximity to road traffic and the risk of death from coronary heart disease," Epidemiology, vol. 21, no. 5, pp. 642-649, 2010.

[9] B. Chaix, M. Rosvall, and J. Merlo, "Assessment of the magnitude of geographical variations and socioeconomic contextual effects on ischaemic heart disease mortality: a multilevel survival analysis of a large Swedish cohort," Journal of Epidemiology and Community Health, vol. 61, no. 4, pp. 349-355, 2007.

[10] B. Chaix, M. Lindström, J. Merlo, and M. Rosvall, "Neighbourhood social interactions and risk of acute myocardial infarction," Journal of Epidemiology and Community Health, vol. 62, no. 1, pp. 62-68, 2008.

[11] C. M. Hoehner, L. K. Brennan Ramirez, M. B. Elliott, S. L. Handy, and R. C. Brownson, "Perceived and objective environmental measures and physical activity among urban adults," American Journal of Preventive Medicine, vol. 28, no. 2, pp. 105-116, 2005.

[12] T. K. Boehmer, C. M. Hoehner, A. D. Deshpande, L. K. Brennan Ramirez, and R. C. Brownson, "Perceived and observed neighborhood indicators of obesity among urban adults," International Journal of Obesity, vol. 31, no. 6, pp. 968977, 2007.

[13] J. H. Tilt, "Walking trips to parks: exploring demographic, environmental factors, and preferences for adults with children in the household," Preventive Medicine, vol. 50, supplement 1, pp. S69-S73, 2010.

[14] S. Inoue, N. Murase, T. Shimomitsu et al., "Association of physical activity and neighborhood environment among Japanese adults," Preventive Medicine, vol. 48, no. 4, pp. 321325, 2009.

[15] T. Sugiyama, E. Leslie, B. Giles-Corti, and N. Owen, "Physical activity for recreation or exercise on neighbourhood streets: associations with perceived environmental attributes," Health and Place, vol. 15, no. 4, pp. 1058-1063, 2009.

[16] M. Duncan and K. Mummery, "Psychosocial and environmental factors associated with physical activity among city dwellers in regional Queensland," Preventive Medicine, vol. 40, no. 4, pp. 363-372, 2005.

[17] N. Humpel, N. Owen, D. Iverson, E. Leslie, and A. Bauman, "Perceived environment attributes, residential location, and walking for particular purposes," American Journal of Preventive Medicine, vol. 26, no. 2, pp. 119-125, 2004.

[18] K. Kondo, J. S. Lee, K. Kawakubo et al., "Association between daily physical activity and neighborhood environments," Environmental Health and Preventive Medicine, vol. 14, no. 3, pp. 196-206, 2009.

[19] T. K. Catlin, E. J. Simoes, and R. C. Brownson, "Environmental and policy factors associated with overweight among adults in Missouri," American Journal of Health Promotion, vol. 17, no. 4, pp. 249-258, 2003.

[20] F. N. Piro, Ø. Nœss, and B. Claussen, "Physical activity among elderly people in a city population: the influence of neighbourhood level violence and self perceived safety," Journal of Epidemiology and Community Health, vol. 60, no. 7, pp. 626-632, 2006.

[21] E. Leslie, E. Cerin, and P. Kremer, "Perceived neighborhood environment and park use as mediators of the effect of 
area socio-economic status on walking behaviors," Journal of Physical Activity and Health, vol. 7, no. 6, pp. 802-810, 2010.

[22] R. D. Tucker-Seeley, S. V. Subramanian, Y. Li, and G. Sorensen, "Neighborhood safety, socioeconomic status, and physical activity in older adults," American Journal of Preventive Medicine, vol. 37, no. 3, pp. 207-213, 2009.

[23] R. A. Harrison, I. Gemmell, and R. F. Heller, "The population effect of crime and neighbourhood on physical activity: an analysis of 15461 adults," Journal of Epidemiology and Community Health, vol. 61, no. 1, pp. 34-39, 2007.

[24] H. Christian, B. Giles-Corti, M. Knuiman, A. Timperio, and S. Foster, "The influence of the built environment, social environment and health behaviors on body mass index. Results from RESIDE," Preventive Medicine, vol. 53, no. 1-2, pp. 57-60, 2011.

[25] J. S. Fish, S. Ettner, A. Ang, and A. F. Brown, "Association of perceived neighborhood safety on body mass index," American Journal of Public Health, vol. 100, no. 11, pp. 2296-2303, 2010.

[26] K. Gebel, A. E. Bauman, T. Sugiyama, and N. Owen, "Mismatch between perceived and objectively assessed neighborhood walkability attributes: prospective relationships with walking and weight gain," Health and Place, vol. 17, no. 2, pp. 519-524, 2011.

[27] E. Blacksher and G. S. Lovasi, "Place-focused physical activity research, human agency, and social justice in public health: taking agency seriously in studies of the built environment," Health and Place, vol. 18, no. 2, pp. 172-179, 2012.

[28] A. H. Auchincloss, A. V. Diez Roux, D. G. Brown, C. A. Erdmann, and A. G. Bertoni, "Neighborhood resources for physical activity and healthy foods and their association with insulin resistance," Epidemiology, vol. 19, no. 1, pp. 146-157, 2008.

[29] T. Boehmer, C. Hoehner, K. Wyrwich, L. Brennan Ramirez, and R. Brownson, "Correspondence between perceived and observed measures of neighborhood environmental supports for physical activity," Journal of Physical Activity and Health, vol. 3, pp. 22-36, 2006.

[30] K. Gebel, A. Bauman, and N. Owen, "Correlates of non-concordance between perceived and objective measures of walkability," Annals of Behavioral Medicine, vol. 37, no. 2, pp. 228 238, 2009.

[31] D. M. Mark, C. Freksa, S. C. Hirtle, R. Lloyd, and B. Tversky, "Cognitive models of geographical space," International Journal of Geographical Information Science, vol. 13, no. 8, pp. 747$774,1999$.

[32] J. J. Gibson, "A theory of direct visual perception," in Vision and Mind: Selected Readings in the Philosophy of Perception, A. Noe and E. Thompson, Eds., Massachusetts Institute of Technology, 2002.

[33] T. F. Saarinen, "Environmental perception," in Perspectives on Environment, I. Manners and M. Mikesell, Eds., pp. 252-289, Association of American Geographers, Commission on College Geography, Washington, DC, USA, 1974.

[34] L. Z. McArthur and R. M. Baron, "Toward an ecological theory of social perception," Psychological Review, vol. 90, no. 3, pp. 215-238, 1983.

[35] S. Cummins, M. Petticrew, L. Sparks, and A. Findlay, "Large scale food retail interventions and diet," British Medical Journal, vol. 330, no. 7493, pp. 683-684, 2005.

[36] B. Chaix, "Geographic life environments and coronary heart disease: a literature review, theoretical contributions, methodological updates, and a research agenda," Annual Review of Public Health, vol. 30, pp. 81-105, 2009.
[37] M. Daniel, S. Moore, and Y. Kestens, "Framing the biosocial pathways underlying associations between place and cardiometabolic disease," Health and Place, vol. 14, no. 2, pp. 117132, 2008.

[38] M. Daniel, P. Lekkas, M. Cargo, I. Stankov, and A. Brown, "Environmental risk conditions and pathways to cardiometabolic diseases in indigenous populations," Annual Review of Public Health, vol. 32, pp. 327-347, 2011.

[39] B. S. McEwen, "Allostasis and allostatic load: implications for neuropsychopharmacology," Neuropsychopharmacology, vol. 22, no. 2, pp. 108-124, 2000.

[40] C. E. Ross and J. Mirowsky, "Neighborhood disadvantage, disorder, and health," Journal of Health and Social Behavior, vol. 42, no. 3, pp. 258-276, 2001.

[41] A. M. Burdette and T. D. Hill, "An examination of processes linking perceived neighborhood disorder and obesity," Social Science and Medicine, vol. 67, no. 1, pp. 38-46, 2008.

[42] J. Sundström, U. Risérus, L. Byberg, B. Zethelius, H. Lithell, and L. Lind, "Clinical value of the metabolic syndrome for long term prediction of total and cardiovascular mortality: prospective, population based cohort study," BMJ, vol. 332, no. 7546, pp. 878-881, 2006.

[43] R. H. Eckel, S. M. Grundy, and P. Z. Zimmet, "The metabolic syndrome," The Lancet, vol. 365, no. 9468, pp. 1415-1428, 2005.

[44] S. M. Grundy, B. Hansen, S. C. Smith, J. I. Cleeman, and R. A. Kahn, "Clinical Management of Metabolic Syndrome: report of the American Heart Association/National Heart, Lung, and Blood Institute/American Diabetes Association Conference on Scientific Issues Related to Management," Circulation, vol. 109, no. 4, pp. 551-556, 2004.

[45] A. J. Cameron, P. Z. Zimmet, J. E. Shaw, and K. G. M. M. Alberti, "The metabolic syndrome: in need of a global mission statement," Diabetic Medicine, vol. 26, no. 3, pp. 306-309, 2009.

[46] J. F. Grant, C. R. Chittleborough, A. W. Taylor et al., "The North West Adelaide Health Study: detailed methods and baseline segmentation of a cohort for selected chronic diseases," Epidemiologic Perspectives and Innovations, vol. 3, article 4, 2006.

[47] J. F. Grant, A. W. Taylor, R. E. Ruffin et al., "Cohort profile: the North West Adelaide Health Study (NWAHS)," International Journal of Epidemiology, vol. 38, no. 6, pp. 1479-1486, 2008.

[48] Australian Bureau of Statistics, South Australia (SSC), Usual Resident Profile: Table U01 Usual Resident Characteristics, retrieved from CDATA 2011, Cat. no. 2004.0, ABS, Canberra, Australia, 2011.

[49] Australian Bureau of Statistics, Statistical Geography: Volume 2-Census Geographic Areas, Australia 2006, Cat. no. 2905.0, ABS, Canberra, Australia, 2007.

[50] International Diabetes Federation, The IDF Consensus Worldwide Definition of the Metabolic Syndrome, International Diabetes Federation, Brussels, Belgium, 2006.

[51] E. Leslie, B. Saelens, L. Frank et al., "Residents' perceptions of walkability attributes in objectively different neighbourhoods: a pilot study," Health and Place, vol. 11, no. 3, pp. 227-236, 2005.

[52] B. E. Saelens, J. F. Sallis, J. B. Black, and D. Chen, "Neighborhood-based differences in physical activity: an environment scale evaluation," American Journal of Public Health, vol. 93, no. 9, pp. 1552-1558, 2003.

[53] A. P. McGinn, K. R. Evenson, A. H. Herring, S. L. Huston, and D. A. Rodriguez, "Exploring associations between physical activity and perceived and objective measures of the built 
environment," Journal of Urban Health, vol. 84, no. 2, pp. 162 $184,2007$.

[54] M. A. Adams, S. Ryan, J. Kerr et al., "Validation of the Neighborhood Environment Walkability Scale (NEWS) items using geographic information systems," Journal of Physical Activity and Health, vol. 6, supplement 1, pp. S113-S123, 2009.

[55] E. Cerin, E. Leslie, N. Owen, and A. Bauman, "An Australian version of the Neighborhood Environment Walkability Scale: validity evidence," Measurement in Physical Education and Exercise Science, vol. 12, no. 1, pp. 31-51, 2008.

[56] E. Cerin, B. E. Saelens, J. F. Sallis, and L. D. Frank, "Neighborhood Environment Walkability Scale: validity and development of a short form," Medicine and Science in Sports and Exercise, vol. 38, no. 9, pp. 1682-1691, 2006.

[57] Australian Bureau of Statistics, National Health Survey: Users Guide, 2001, Cat. no. 4363.0.55.001, ABS, Canberra, Australia, 2003.

[58] W. J. Brown, S. G. Trost, A. Bauman, K. Mummery, and N. Owen, "Test-retest reliability of four physical activity measures used in population surveys," Journal of Science and Medicine in Sport, vol. 7, no. 2, pp. 205-215, 2004.

[59] Australian Bureau of Statistics, Basic Community Profile (BCP) DataPack (First/Second Release), Australia 2006, Cat. no. 2069.0.30.001, ABS, Canberra, Australia, 2007.

[60] R. M. Baron and D. A. Kenny, "The moderator-mediator variable distinction in social psychological research: conceptual, strategic, and statistical considerations," Journal of Personality and Social Psychology, vol. 51, no. 6, pp. 1173-1182, 1986.

[61] J. P. Selig and K. J. Preacher, "Monte Carlo method for assessing mediation: an interactive tool for creating confidence intervals for indirect effects," 2008, http://quantpsy.org/.

[62] A. F. Hayes, "Beyond Baron and Kenny: statistical mediation analysis in the new millennium," Communication Monographs, vol. 76, no. 4, pp. 408-420, 2009.

[63] B. Chaix, M. Rosvall, and J. Merlo, "Recent increase of neighborhood socioeconomic effects on ischemic heart disease mortality: a multilevel survival analysis of two large Swedish cohorts," American Journal of Epidemiology, vol. 165, no. 1, pp. 22-26, 2007.

[64] R. E. Foraker, K. M. Rose, A. M. Kucharska-Newton, H. Ni, C. M. Suchindran, and E. A. Whitsel, "Variation in rates of fatal coronary heart disease by neighborhood socioeconomic status: the Atherosclerosis Risk in Communities surveillance (1992-2002)," Annals of Epidemiology, vol. 21, no. 8, pp. 580$588,2011$.

[65] M. Janghorbani, R. B. Jones, and R. Nelder, "Neighbourhood deprivation and excess coronary heart disease mortality and hospital admissions in Plymouth, UK: an ecological study," Acta Cardiologica, vol. 61, no. 3, pp. 313-320, 2006.

[66] K. Sundquist, M. Winkleby, H. Ahlén, and S. E. Johansson, "Neighborhood socioeconomic environment and incidence of coronary heart disease: a follow-up study of 25,319 women and men in Sweden," American Journal of Epidemiology, vol. 159, no. 7, pp. 655-662, 2004.

[67] F. Tabassum, E. Breeze, and M. Kumari, "Coronary heart disease risk factors and regional deprivation in England: does age matter?" Age and Ageing, vol. 39, no. 2, Article ID afp205, pp. 253-256, 2009.

[68] A. V. Diez Roux, D. R. Jacobs, and C. I. Kiefe, "Neighborhood characteristics and components of the insulin resistance syndrome in young adults: the Coronary Artery Risk Development in Young Adults (CARDIA) Study," Diabetes Care, vol. 25, no. 11, pp. 1976-1982, 2002.

[69] R. W. Morris, G. Wannamethee, L. T. Lennon, M. C. Thomas, and P. H. Whincup, "Do socioeconomic characteristics of neighbourhood of residence independently influence incidence of coronary heart disease and all-cause mortality in older British men?" European Journal of Cardiovascular Prevention and Rehabilitation, vol. 15, no. 1, pp. 19-25, 2008.

[70] C. Cubbin and M. A. Winkleby, "Protective and harmful effects of neighborhood-level deprivation on individual-level health knowledge, behavior changes, and risk of coronary heart disease," American Journal of Epidemiology, vol. 162, no. 6, pp. 559-568, 2005.

[71] A. V. Diez-Roux, F. J. Nieto, C. Muntaner et al., "Neighborhood environments and coronary heart disease: a multilevel analysis," American Journal of Epidemiology, vol. 146, no. 1, pp. 48-63, 1997.

[72] A. Petrelli, R. Gnavi, C. Marinacci, and G. Costa, "Socioeconomic inequalities in coronary heart disease in Italy: a multilevel population-based study," Social Science and Medicine, vol. 63, no. 2, pp. 446-456, 2006.

[73] B. Chaix, M. Rosvall, and J. Merlo, "Neighborhood socioeconomic deprivation and residential instability: effects on incidence of ischemic heart disease and survival after myocardial infarction," Epidemiology, vol. 18, no. 1, pp. 104-111, 2007.

[74] L. R. Mobley, E. D. Root, E. A. Finkelstein, O. Khavjou, R. P. Farris, and J. C. Will, "Environment, obesity, and cardiovascular disease risk in low-income women," American Journal of Preventive Medicine, vol. 30, no. 4, pp. 327-332, 2006.

[75] K. Sundquist, H. Theobald, M. Yang, X. Li, S. E. Johansson, and J. Sundquist, "Neighborhood violent crime and unemployment increase the risk of coronary heart disease: a multilevel study in an urban setting," Social Science and Medicine, vol. 62, no. 8, pp. 2061-2071, 2006.

[76] B. Hoffmann, S. Moebus, A. Stang et al., "Residence close to high traffic and prevalence of coronary heart disease," European Heart Journal, vol. 27, no. 22, pp. 2696-2702, 2006.

[77] J. Sundquist, S. E. Johansson, M. Yang, and K. Sundquist, "Low linking social capital as a predictor of coronary heart disease in Sweden: a cohort study of 2.8 million people," Social Science and Medicine, vol. 62, no. 4, pp. 954-963, 2006.

[78] A. H. Auchincloss, A. V. Diez Roux, D. G. Brown, E. S. O'Meara, and T. E. Raghunathan, "Association of insulin resistance with distance to wealthy areas: the Multi-Ethnic Study of Atherosclerosis," American Journal of Epidemiology, vol. 165, no. 4, pp. 389-397, 2007.

[79] S. Cummins, M. Petticrew, C. Higgins, A. Findlay, and L. Sparks, "Large scale food retailing as an intervention for diet and health: quasi-experimental evaluation of a natural experiment," Journal of Epidemiology and Community Health, vol. 59, no. 12, pp. 1035-1040, 2005.

[80] J. Boone-Heinonen, P. Gordon-Larsen, C. I. Kiefe, J. M. Shikany, C. E. Lewis, and B. M. Popkin, "Fast food restaurants and food stores-longitudinal associations with diet in young to middle-aged adults: the CARDIA study," Archives of Internal Medicine, vol. 171, no. 13, pp. 1162-1170, 2011.

[81] P. Skrabanek, "The emptiness of the black box," Epidemiology, vol. 5, no. 5, pp. 553-555, 1994.

[82] T. A. Glass, M. D. Rasmussen, and B. S. Schwartz, "Neighborhoods and obesity in older adults. The Baltimore Memory Study," American Journal of Preventive Medicine, vol. 31, no. 6, pp. 455-463, 2006.

[83] M. S. Mujahid, A. V. D. Roux, M. Shen et al., "Relation between neighborhood environments and obesity in the multi-ethnic study of atherosclerosis," American Journal of Epidemiology, vol. 167, no. 11, pp. 1349-1357, 2008.

[84] W. Poortinga, "Perceptions of the environment, physical activity, and obesity," Social Science and Medicine, vol. 63, no. 11, pp. 2835-2846, 2006. 
[85] D. Kim, A. V. Diez Roux, C. I. Kiefe, I. Kawachi, and K. Liu, "Do neighborhood socioeconomic deprivation and low social cohesion predict coronary calcification?" American Journal of Epidemiology, vol. 172, no. 3, pp. 288-298, 2010.

[86] K. Steenland, J. Henley, E. Calle, and M. Thun, "Individualand area-level socioeconomic status variables as predictors of mortality in a cohort of 179,383 persons," American Journal of Epidemiology, vol. 159, no. 11, pp. 1047-1056, 2004. 


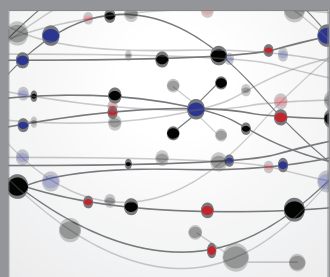

The Scientific World Journal
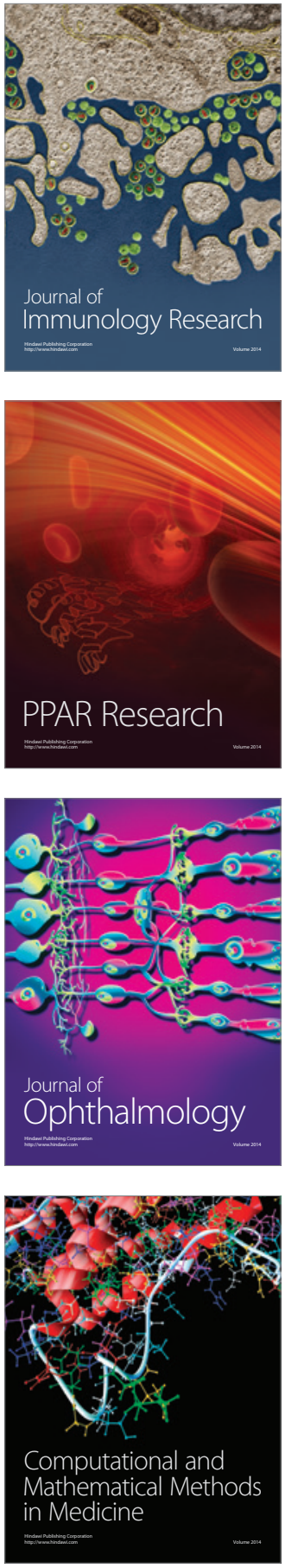

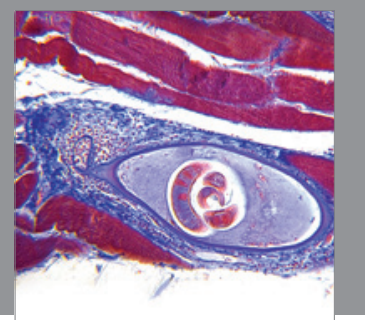

Gastroenterology

Research and Practice
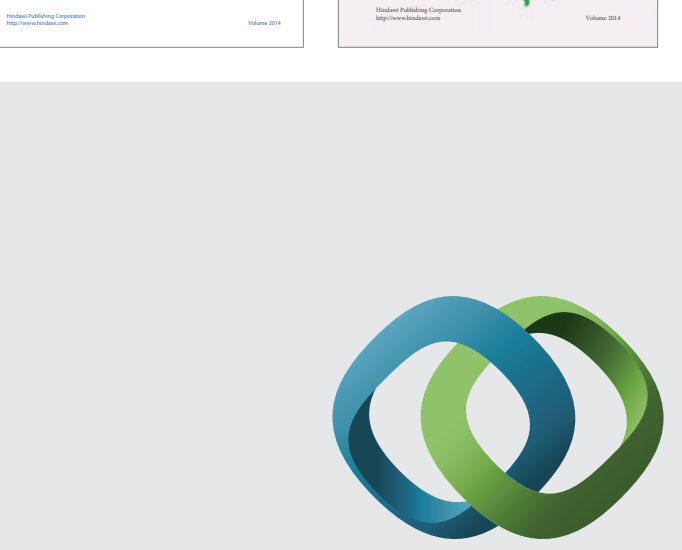

\section{Hindawi}

Submit your manuscripts at

http://www.hindawi.com
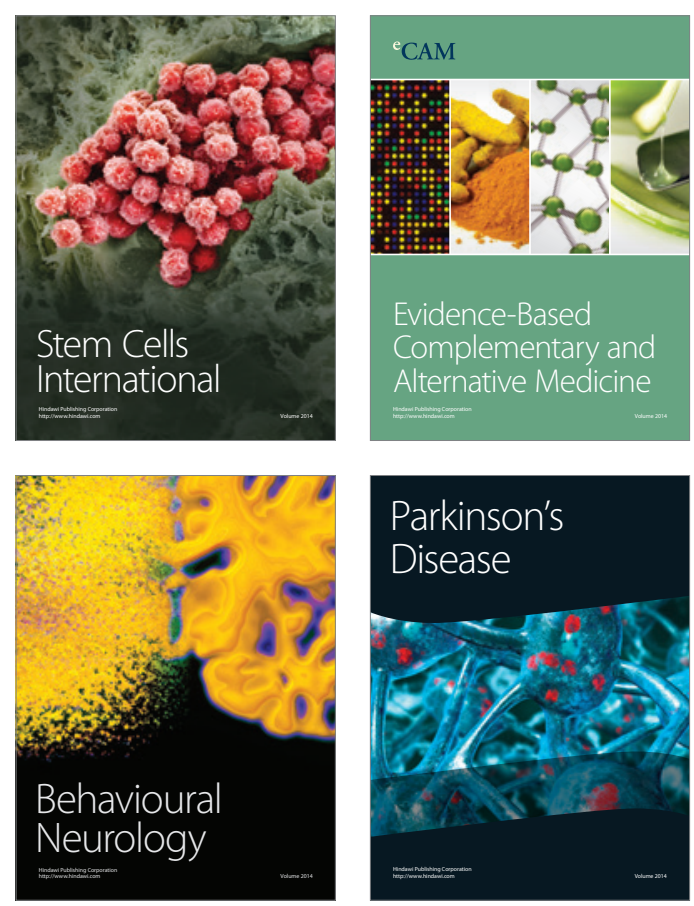

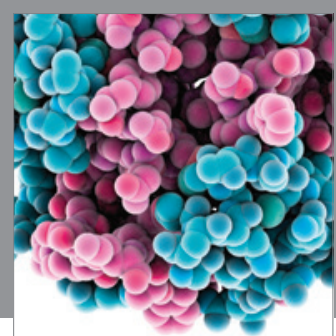

Journal of
Diabetes Research

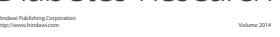

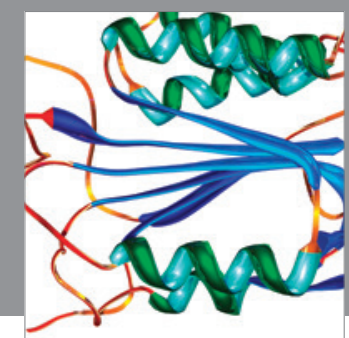

Disease Markers
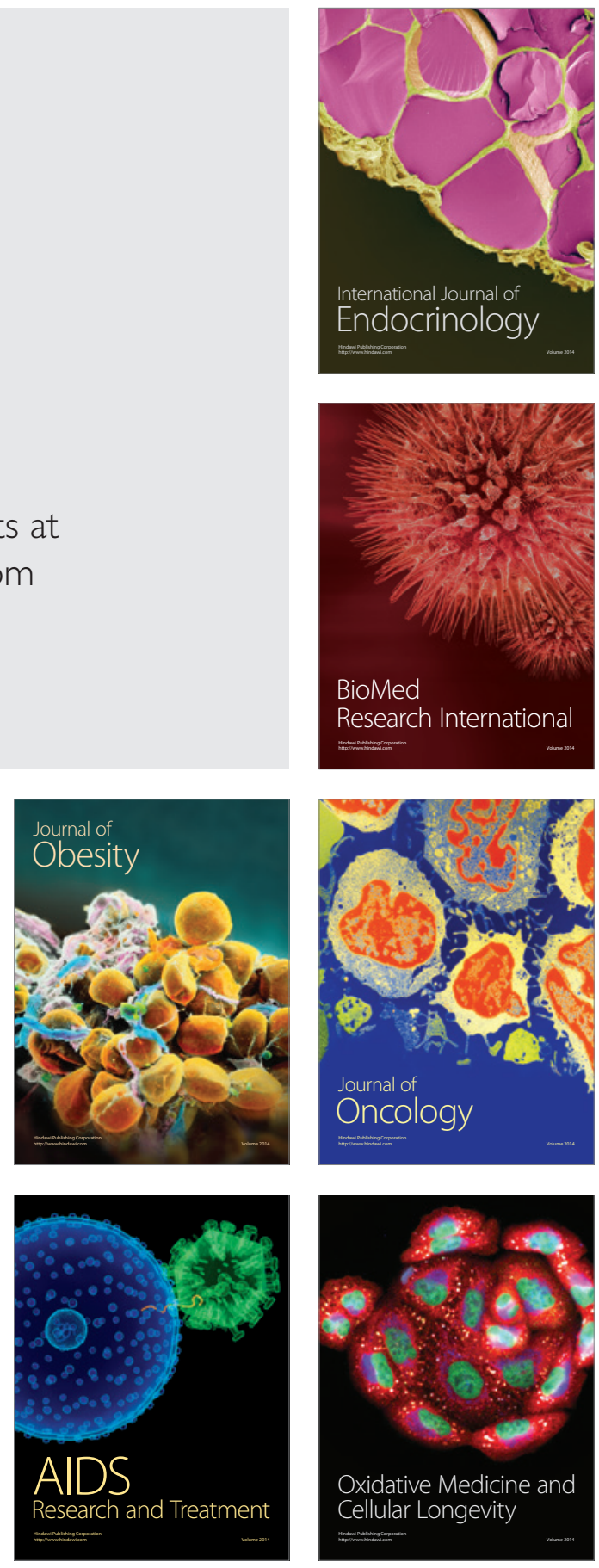